\title{
Letter
}

\section{Why the devil does not have the best tunes: a response to Verissimo \& McKinley}

Verissimo \& McKinley (2016) outlined a growing interest amongst practitioners and researchers in so-called conservation marketing. Here, the basic precepts of commercial marketing are adapted and deployed to influence human behaviour, encouraging positive social and environmental outcomes through the use of the well-established tools of social marketing. These tools include framing and targeting messages to pre-identified segments of the population in appeals to donate money to a conservation organization or to buy a more sustainable product. Such appeals are tailored to match the values of the target audience, thus allegedly making an altered behaviour more likely.

As Verissimo \& McKinley (2016) point out, social marketing has been around for decades and has had positive impacts in fields such as public health. They suggest that conservationists' apparent unease at making use of social marketing tools is attributable to its origins in the 'dark arts' of commercial marketing: the very sector that has encouraged the unfettered growth and hyper-consumerism that underpin many environmental challenges. Whilst this may be true, I argue here that the unease of others-particularly many social scientists-comes rather from a strong empirical evidence base, as well as conceptual innovations, which together clearly outline the ineffectiveness of social marketing at altering behaviour towards more environmentally sustainable ends.

Since the 1980 os there has been a lively policy and research debate around the issue of sustainable consumption; that is, the ways and means to enable people to meet their material needs in an environmentally and socially sustainable manner. As this agenda has gained momentum under the rubric of sustainable development, numerous charities, governments, researchers and activists have experimented with manifold forms of behavioural interventions, including those of social marketing. This has ranged from exhortations to 'do our bit' for the planet when, for example, heating our homes (i.e. use less energy), to structured programmes that aim to guide households and businesses through practical actions to save resources, such as in the work of the charity Global Action Plan. Although results have been complex and varied, the prevailing finding is that social marketing alone is an ineffective means to encourage sustained and sustainable behaviour change, and misreads and misrepresents the enormity of the challenges faced when trying to influence human behaviour.
Why is this the case? All of our consumption choices are mediated by a complex array of internal and external factors, which include personal habits and values, shared norms, prices, social trends, trust in institutions and corporations, as well as (mis)trust in others to also 'do their bit'. Given all of these factors, it should not be surprising that few changes in behaviour result from social marketing, and those that do are either part of a broader suite of more sustained interventions or are likely to break down if one of the above factors change, as they often do. Social marketing also aims to influence consumption behaviours one at a time, failing to account for the existence of rebound effects (I saved money on my gas bill to help the environment, now for a new pair of shoes!) and moral licensing (I have done my bit and am a good person, so I can splurge on a holiday overseas).

One response to such critiques could be to try conservation marketing anyway, as even if results are small they are at least results. However, evidence around the field of sustainable and environmental consumption (e.g. Corner \& Randall, 2011; Hobson, 2003; Young \& Middlemiss, 2012) suggests this may not only be an inefficient use of precious time and resources but also oversimplifies the socially, culturally and politically complex challenges of changing all of our behaviours. This is why current social science research on this topic is more interested in questions of how to alter the production-consumption systems in which behaviours-or rather practices-are embedded, having realized that utilizing the tools for marketing jeans or coffee does not have the same impact when used for marketing environmental and social goods.

KeRSTY HoBSON School of Geography and Planning, Cardiff University, UK. E-mail hobsonk@cardiff.ac.uk

\section{References}

Corner, A. \& Randall, A. (2011) Selling climate change? The limitations of social marketing as a strategy for climate change public engagement. Global Environmental Change, 21, 1005-1014.

Hobson, K. (2003) Thinking habits into action: the role of knowledge and process in questioning household consumption practices. Local Environment, 8, 95-112.

Veríssimo, D. \& McKinley, E. (2016) Introducing conservation marketing: why should the devil have all the best tunes? Oryx, 50, 14.

Young, W. \& Middlemiss, L. (2012) A rethink of how policy and social science approach changing individuals' actions on greenhouse gas emissions. Energy Policy, 41, 742-747. 